\title{
latrogenic retinal breaks and postoperative retinal detachments in microincision vitrectomy surgery compared with conventional 20-gauge vitrectomy: a meta-analysis
}

\author{
G. H. Chen ${ }^{1} \cdot$ R. Tzekov ${ }^{2}$ - F. Z. Jiang ${ }^{1} \cdot$ S. H. Mao ${ }^{1}$ Y. H. Tong ${ }^{1} \cdot$ W. S. Li $^{3,4}$
}

Received: 27 August 2018 / Revised: 4 November 2018 / Accepted: 17 November 2018 / Published online: 18 December 2018

(c) The Royal College of Ophthalmologists 2018

\begin{abstract}
Purpose To assess the incidence of iatrogenic retinal breaks (IRBs) and postoperative retinal detachments (RDs) in microincision vitrectomy surgery (MIVS) compared with 20-gauge (20 G) vitrectomy.

Methods A comprehensive literature search was performed to find relevant studies and a meta-analysis of the IRBs and postoperative RDs rates after $20 \mathrm{G}$ vitrectomy versus MIVS was conducted.

Results Thirty-two studies were selected, including 14,373 eyes (6932 eyes in the $20 \mathrm{G}$ group, 7441 eyes in the MIVS group). The meta-analysis demonstrated that the incidence of IRBs was significantly higher in $20 \mathrm{G}$ vitrectomy vs. MIVS $(\mathrm{OR}=2.22,95 \% \mathrm{CI}, 1.93-2.57, P<0.00001)$ and in a subanalysis vs. $23 \mathrm{G}$ MIVS (OR $=2.19,95 \% \mathrm{CI}, 1.87-2.56, P<$ $0.00001)$ and vs. $25 \mathrm{G}$ MIVS (OR $=2.27,95 \% \mathrm{CI}, 1.62-3.18, P<0.00001)$. Similar result was obtained in a subanalysis for macular surgery $(\mathrm{OR}=2.44,95 \% \mathrm{CI}, 1.99-2.99, P<0.00001)$, and also for sclerotomy-related IRBs $(\mathrm{OR}=3.73,95 \% \mathrm{CI}$, $2.55-5.44, P<0.00001)$, but not for surgically induced posterior vitreous detachment-related IRBs $(\mathrm{OR}=1.59,95 \% \mathrm{CI}$, $0.89-2.84, P=0.12$ ). The incidence of postoperative RDs in $20 \mathrm{G}$ vitrectomy was significantly higher compared to MIVS $(\mathrm{OR}=1.72,95 \% \mathrm{CI}, 1.21-2.46, P=0.003)$ and in a subanalysis vs. $23 \mathrm{G}$ MIVS (OR $=2.45,95 \% \mathrm{CI}, 1.50-4.00, P=$ 0.0003 ), but not for $25 \mathrm{G}$ MIVS ( $\mathrm{OR}=1.01,95 \% \mathrm{CI}, 0.63-1.64, P=0.96)$. Similar result was obtained in a subanalysis for macular surgery $(\mathrm{OR}=1.89,95 \% \mathrm{CI}, 1.26-2.85, P=0.002)$.

Conclusion This meta-analysis demonstrated that MIVS is associated with a lower risk of IRBs and postoperative RDs compared to $20 \mathrm{G}$ vitrectomy.
\end{abstract}

These authors contributed equally: G. H. Chen, R. Tzekov.

Supplementary information The online version of this article (https:// doi.org/10.1038/s41433-018-0319-5) contains supplementary material, which is available to authorized users.

W. S. Li

drlws@qq.com

1 Department of Ophthalmology, Quzhou People's Hospital, Quzhou, Zhejiang, People's Republic of China

2 Department of Ophthalmology, University of South Florida, Tampa, FL, USA

3 Shanghai Aier Eye Hospital, 1286 Hongqiao Road, Shanghai, People's Republic of China

4 Aier School of Ophthalmology, Central South University, Changsha, Hunan Province, People's Republic of China

\section{Introduction}

Pars plana vitrectomy (PPV) based on 20-gauge instruments $(20 \mathrm{G})$ has become and remained a widely used vitreoretinal surgical procedure and an essential therapeutic approach in many vitreoretinal diseases since 1975 [1]. This conventional $20 \mathrm{G}$ PPV surgery requires the closure of the sclerotomies with sutures at the end of surgery to prevent wound leakage. In contrast, the introduction of smaller diameter instruments in the mid-2000s do not require placement of scleral sutures because of the self-sealing nature of the wounds. This surgical method is also known as microincision vitrectomy surgery (MIVS) and can be achieved with the use of 23-gauge ( $23 \mathrm{G}), 25$-gauge ( $25 \mathrm{G}$ ) or 27 -guage $(27 \mathrm{G})$ instruments, although the $27 \mathrm{G}$ method is still much less widely used compared to the other two methods. MIVS is gaining popularity for the surgical treatment of several vitreoretinal diseases since it was introduced due to many potential advantages, including 
reduction in inflammation, patient discomfort, shorter recovery time, and in some cases, shorter duration of surgery [2].

Recently, a meta-analysis demonstrated that 23 G MIVS may carry similar risk of postoperative endophthalmitis compared to conventional $20 \mathrm{G}$ vitrectomy and $25 \mathrm{G}$ MIVS may carry slightly higher rate of postoperative endophthalmitis [3]. However, it is not clear if such differences appear in other complications of vitrectomy. Despite continuous advances to improve safety of both traditional $20 \mathrm{G}$ PPV and MIVS, iatrogenic retinal breaks (IRBs) and postoperative retinal detachments (RDs) remain major complications of this type of surgery, usually necessitating a subsequent treatment during surgery (either cryopexy or laser) or even repeat surgery and frequently impacting visual outcomes [4]. The overall incidence of IRBs associated with $20 \mathrm{G}$ vitrectomy in the published literature ranges from 1.4 to $44 \%$ [5-7], which appears to be somewhat higher compared to the published frequency of IRBs in MIVS, which has a range of $1.1-16 \%$ [8-10]. The incidence of the other major complication-postoperative RDs after $20 \mathrm{G}$ vitrectomy has been reported to be between 0.8 and $9.8 \%$ [11-13]. While some studies have evidenced postoperative RDs following MIVS, the incidence after this type of surgery seems to be generally lower compared to IRBs, ranging from 1 to $1.6 \%[8,10,14]$. However, there is still some controversy about whether MIVS carries comparable risk of IRBs and postoperative RDs compared to conventional $20 \mathrm{G}$ vitrectomy and an aggregate analysis of suitable comparative studies is lacking.

Thus far, only one meta-analysis published in 2013 reported complications in MIVS compared to $20 \mathrm{G}$ vitrectomy, indicating that there are no statistically significant differences between groups regarding incidence rates of choroidal detachment, vitreous hemorrhage, and postoperative RDs [2]. It included only four trials in the comparison of postoperative RDs. Furthermore, we are not aware of any meta-analysis focused on comparing the incidence of IRBs associated with both types of surgery. The availability of more recent relevant data stimulated us to undertake a new meta-analysis in order to get more informed conclusions about the incidence of these two complications in MIVS and traditional $20 \mathrm{G}$ vitrectomy.

\section{Materials and methods}

\section{Search strategy}

We selected relevant studies by searching PubMed, ISI Web of Science and Embase, using the terms "pars plana vitrectomy" or "vitrectomy" or "20-gauge" and "23-gauge" or "25-gauge" or "27-gauge" or "transconjunctival sutureless vitrectomy" or "microincision vitrectomy" or "small gauge vitrectomy", with the language restricted to English, up to July 23, 2018. Reference lists of all retrieved articles were also searched manually.

\section{Inclusion and exclusion criteria}

We included studies in this meta-analysis if the studies met the following inclusion criteria: (1) comparative cases series studies reporting the IRBs and postoperative RDs rates in all types of MIVS (23 G, $25 \mathrm{G}, 27 \mathrm{G}$ ) versus $20 \mathrm{G}$ vitrectomy, (2) independent prospective or retrospective studies that provided the data to estimate odds ratios (OR) with 95\% confidence interval (CI). Articles with repeat data, abstracts from conferences, letters, case reports, and review articles were also excluded.

\section{Data extraction}

Two authors (GHC and WSL) selected relevant studies and extracted the data. Uncertainty was resolved by discussion. The following items were collected: first author's name, the year of publication, study design, country of origin, participant numbers in each group, and incidence of IRBs and postoperative RDs.

\section{Qualitative assessment}

We adopted the Newcastle Ottawa Scale (NOS) to evaluate the quality of nonrandomized studies by a modified checklist [15], which has an eight-item scale based on three criteria: selection, comparability, and outcome. Studies with NOS score above 7 points were defined as high quality; as medium quality if they were between 4 and 6 points; otherwise they were poor quality. We only included the studies with NOS score above four points. The qualities of randomized clinical trials (RCTs) were assessed by Jadad scale [16], which is a 5-point scale, assigning scores for reported randomization, masking and participant withdrawals. Studies scoring less than 3 points were excluded from this study.

\section{Statistical analysis}

The Cochrane Review Manager (RevMan, software version 5.1, Copenhagen, Denmark: The Nordic Cochrane Center, The Cochrane Collaboration, 2011) was used for all statistical analyses. The OR of IRBs and postoperative RDs comparing MIVS with conventional $20 \mathrm{G}$ vitrectomy were measured, and outcomes were reported with a 95\% CI. Subgroup analyses based on macular surgery and different types of MIVS were conducted. Subgroup estimates by type 
Table 1 Characteristics of the studies included in the meta-analysis

\begin{tabular}{|c|c|c|c|c|c|c|c|c|c|c|c|}
\hline & \multirow[t]{3}{*}{ Study } & \multirow[t]{3}{*}{ Location } & \multirow[t]{3}{*}{ Disease } & \multicolumn{4}{|c|}{$\begin{array}{l}\text { Iatrogenic retinal } \\
\text { breaks }\end{array}$} & \multicolumn{4}{|c|}{$\begin{array}{l}\text { Postoperative retinal } \\
\text { detachments }\end{array}$} \\
\hline & & & & \multicolumn{2}{|c|}{$20 \mathrm{G}$} & \multicolumn{2}{|c|}{$\begin{array}{l}\text { MIVS }(23 \\
\text { G or } 25 \mathrm{G})\end{array}$} & \multicolumn{2}{|c|}{$20 \mathrm{G}$} & \multicolumn{2}{|c|}{$\begin{array}{l}\text { MIVS } \\
(23 \mathrm{G} \text { or } \\
25 \mathrm{G})\end{array}$} \\
\hline & & & & $n$ & $T$ & $n$ & $T$ & $n$ & $T$ & $n$ & $T$ \\
\hline 1. & Albrieux et al. [20] & France & Rhegmattogenous retinal detachment & 2 & 35 & 3 & 35 & l & l & l & l \\
\hline 2. & Cha et al. [21] & Korea & Multiple vitreoretinal diseases & 25 & 402 & 16 & 973 & I & l & l & l \\
\hline 3. & Covert et al. [5] & USA & Macular pucker and macular hole & 47 & 204 & 6 & 152 & 12 & 204 & 6 & 152 \\
\hline 4. & $\begin{array}{l}\text { Dihowm and MacCumber } \\
\text { [24] }\end{array}$ & USA & Idiopathic macular hole & l & l & l & l & 2 & 37 & 2 & 105 \\
\hline 5. & Goncu et al. [25] & Turkey & $\begin{array}{l}\text { Idiopathic epiretinal membrane and macular } \\
\text { hole }\end{array}$ & l & l & l & l & 1 & 31 & 0 & 33 \\
\hline 6. & Gosse et al. [6] & UK & $\begin{array}{l}\text { Epiretinal membrane, vitreomacular traction } \\
\text { and macular hole }\end{array}$ & 22 & 50 & 9 & 50 & l & I & l & l \\
\hline 7. & Haas et al. [8] & Austria & Epireinal membrane & l & l & l & l & 3 & 167 & 1 & 64 \\
\hline 8. & Hikichi et al. [7] & Japan & Preretinal membrane & 3 & 50 & 4 & 50 & I & l & l & / \\
\hline 9. & Hikichi et al. [9] & Japan & Idiopathic macular holes & 7 & 50 & 6 & 50 & l & l & l & l \\
\hline 10. & Hikichi et al. [10] & Japan & Macular holes or preretinal membranes & 10 & 61 & 20 & 122 & 0 & 61 & 2 & 122 \\
\hline 11. & Issa et al. [27] & UK & Proliferative diabetic retinopathy & 16 & 85 & 6 & 85 & 1 & 85 & 1 & 85 \\
\hline 12 & Jalil et al. [26] & UK & Macular hole & 105 & 628 & 23 & 296 & 7 & 628 & 2 & 296 \\
\hline 13. & Krishnan et al. [28] & UK & Idiopathic macular hole & 13 & 36 & 4 & 36 & l & I & l & l \\
\hline 14. & Misra et al. [22] & UK & Multiple vitreoretinal diseases & 7 & 50 & 6 & 50 & l & l & l & l \\
\hline 15 . & Nagpal et al. [30] & India & Multiple vitreoretinal diseases & l & l & l & l & 2 & 30 & 0 & 60 \\
\hline 16. & Nakano et al. [29] & Japan & $\begin{array}{l}\text { Idiopathic epiretinal membrane and macular } \\
\text { hole }\end{array}$ & 13 & 153 & 2 & 176 & I & l & l & l \\
\hline 17. & Neffendorf et al. [31] & UK & Multiple vitreoretinal diseases & 309 & 2648 & 99 & 1626 & l & l & l & l \\
\hline 18. & Neuhann et al. [32] & Germany & Epiretinal membrane & 28 & 111 & 14 & 110 & l & l & l & I \\
\hline 19. & Park et al. [23] & Korea & Proliferative diabetic retinopathy & 10 & 66 & 3 & 35 & / & l & l & / \\
\hline 20. & Pielen et al. [11] & Germany & Epiretinal membrane and macular hole & 12 & 61 & 7 & 59 & 6 & 61 & 0 & 59 \\
\hline 21. & Rizzo et al. [14] & Italy & Macular hole and epiretinal membrane & l & l & l & l & 7 & 570 & 31 & 1862 \\
\hline 22. & Le Rouic et al. [12] & France & $\begin{array}{l}\text { Epiretinal membrane, macular hole and } \\
\text { vitreomacular traction }\end{array}$ & 5 & 346 & 4 & 349 & 17 & 346 & 4 & 349 \\
\hline 23. & Sandali et al. [13] & France & Epiretinal membrane & 29 & 347 & 9 & 206 & 3 & 347 & 0 & 206 \\
\hline 24. & Scartozzi et al. [33] & USA & Macular pucker and macular hole & 14 & 219 & 4 & 128 & / & l & l & l \\
\hline 25 . & Shinoda et al. [34] & Japan & Macular hole & 8 & 23 & 4 & 23 & l & l & l & l \\
\hline 26. & Tan et al. [35] & The Netherlands & Floaters & 6 & 29 & 13 & 87 & / & l & l & l \\
\hline 27. & Tosi et al. [36] & Italy & Macular hole and epiretinal membrane & 11 & 109 & 3 & 145 & 2 & 109 & 0 & 145 \\
\hline 28. & Valmaggia [37] & Switzerland & Idiopathic epiretinal membranes & I & l & l & l & 3 & 64 & 0 & 75 \\
\hline 29. & Wickham et al. [38] & UK & Multiple vitreoretinal diseases & 5 & 21 & 1 & 18 & 0 & 21 & 1 & 18 \\
\hline 30 & Wimpissinger et al. [39] & Austria & Multiple vitreoretinal diseases & 1 & 30 & 1 & 30 & 1 & 30 & 1 & 30 \\
\hline 31 & Yokota et al. [40] & Japan & Proliferative diabetic retinopathy & 60 & 170 & 62 & 254 & 7 & 170 & 10 & 254 \\
\hline 32 & Zhang et al. [41] & China & Multiple vitreoretinal diseases & 3 & 49 & 1 & 97 & 2 & 49 & 2 & 97 \\
\hline \multicolumn{4}{|c|}{ All studies } & 771 & 6033 & 330 & 5242 & 76 & 3010 & 63 & 4012 \\
\hline
\end{tabular}

$G$ gauge, MIVS microincision vitrectomy surgery, $n$ number of iatrogenic retinal breaks/postoperative retinal detachments, $T$ total cases, / not available

Multiple vitreoretinal diseases_rhegmatogenous retinal detachment, macular hole, macular membrane, vitreous hemorrhage, retinal vein occlusion, diabetic retinopathy or others

of IRBs (sclerotomy-related retinal breaks or surgically induced posterior vitreous detachment (PVD)-related retinal breaks) were also conducted. We used the Q statistic-test to calculate heterogeneity between studies [17]. If $P<0.05$, a 


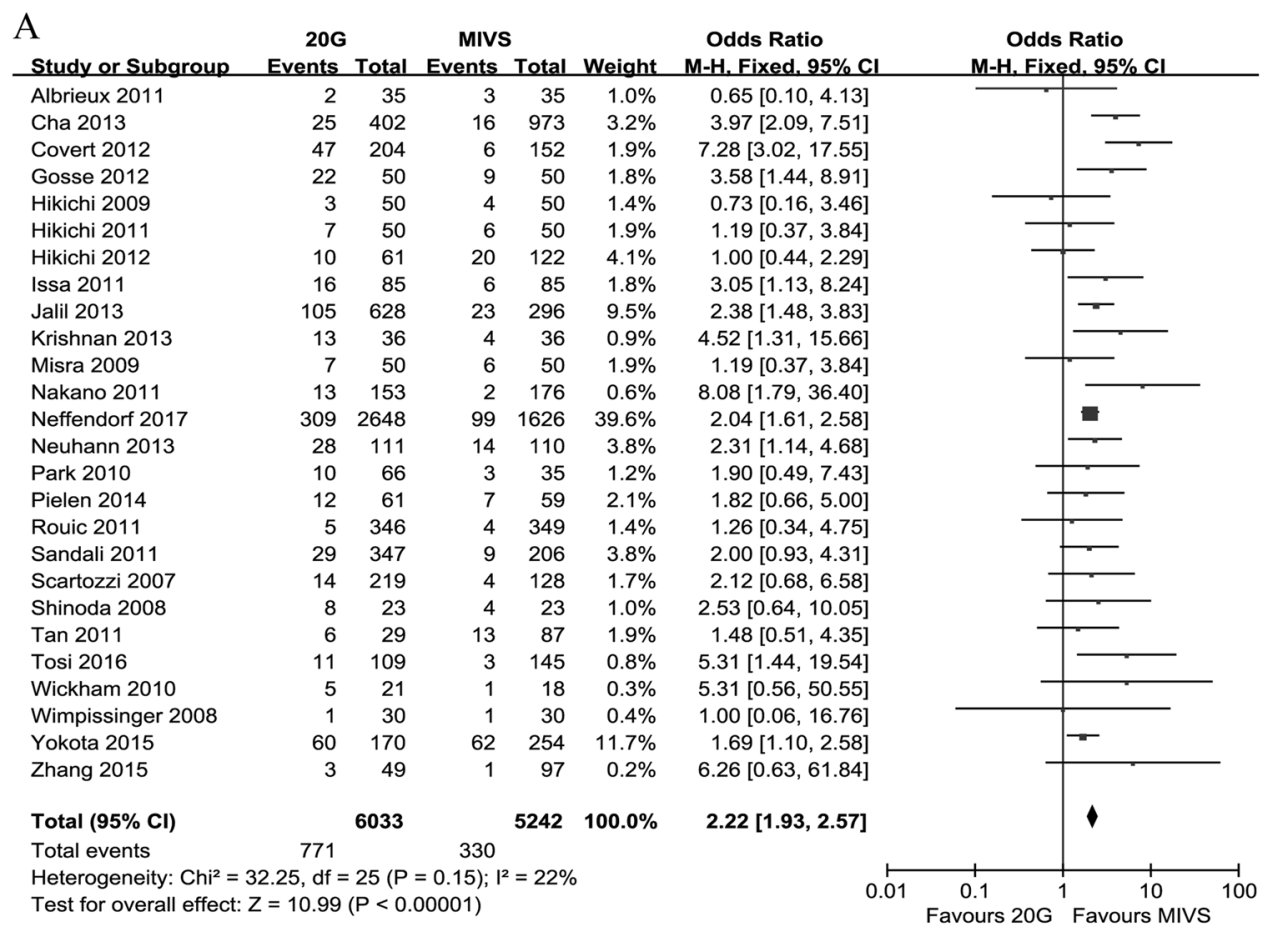

B

\begin{tabular}{|c|c|c|c|c|c|c|c|c|}
\hline Study or Subgroup & $\begin{array}{l}20 G \\
\text { Events }\end{array}$ & Total & $\begin{array}{r}\text { 23G } \\
\text { Events }\end{array}$ & Total & Weight & $\begin{array}{l}\text { Odds Ratio } \\
\text { M-H. Fixed. } 95 \% \text { Cl }\end{array}$ & $\begin{array}{r}\text { Odds } \\
\text { M-H. Fixe }\end{array}$ & $\begin{array}{l}\text { Ratio } \\
\text { d. } 95 \% \mathrm{Cl}\end{array}$ \\
\hline Albrieux 2011 & 2 & 35 & 3 & 35 & $1.2 \%$ & $0.65[0.10,4.13]$ & & \\
\hline Cha 2013 & 25 & 402 & 16 & 973 & $3.8 \%$ & $3.97[2.09,7.51]$ & & - \\
\hline Covert 2012 & 47 & 204 & 3 & 76 & $1.5 \%$ & $7.28[2.19,24.18]$ & & \\
\hline Gosse 2012 & 22 & 50 & 9 & 50 & $2.2 \%$ & $3.58[1.44,8.91]$ & & \\
\hline Hikichi 2009 & 3 & 50 & 4 & 50 & $1.6 \%$ & $0.73[0.16,3.46]$ & & \\
\hline Hikichi 2011 & 7 & 50 & 6 & 50 & $2.3 \%$ & $1.19[0.37,3.84]$ & & \\
\hline Hikichi 2012 & 10 & 61 & 20 & 122 & $4.9 \%$ & $1.00[0.44,2.29]$ & & - \\
\hline Issa 2011 & 16 & 85 & 6 & 85 & $2.1 \%$ & $3.05[1.13,8.24]$ & & \\
\hline Jalil 2013 & 105 & 628 & 23 & 296 & $11.4 \%$ & $2.38[1.48,3.83]$ & & $=$ \\
\hline Krishnan 2013 & 13 & 36 & 4 & 36 & $1.1 \%$ & $4.52[1.31,15.66]$ & & \\
\hline Misra 2009 & 7 & 50 & 6 & 50 & $2.3 \%$ & $1.19[0.37,3.84]$ & & \\
\hline Nakano 2011 & 13 & 153 & 2 & 176 & $0.7 \%$ & $8.08[1.79,36.40]$ & & \\
\hline Neffendorf 2017 & 309 & 2648 & 99 & 1626 & $47.5 \%$ & $2.04[1.61,2.58]$ & & $\mathbf{E}$ \\
\hline Park 2010 & 10 & 66 & 3 & 35 & $1.5 \%$ & $1.90[0.49,7.43]$ & & \\
\hline Pielen 2014 & 12 & 61 & 7 & 59 & $2.5 \%$ & $1.82[0.66,5.00]$ & & \\
\hline Rouic 2011 & 5 & 346 & 4 & 349 & $1.7 \%$ & $1.26[0.34,4.75]$ & & \\
\hline Sandali 2011 & 29 & 347 & 7 & 115 & $4.2 \%$ & $1.41[0.60,3.30]$ & & - \\
\hline Wimpissinger 2008 & 1 & 30 & 1 & 30 & $0.4 \%$ & $1.00[0.06,16.76]$ & & \\
\hline Yokota 2015 & 60 & 170 & 17 & 80 & $6.6 \%$ & $2.02[1.09,3.76]$ & & $=$ \\
\hline Zhang 2015 & 3 & 49 & 1 & 97 & $0.3 \%$ & $6.26[0.63,61.84]$ & & \\
\hline Total $(95 \% \mathrm{Cl})$ & & 5521 & & 4390 & $100.0 \%$ & $2.19[1.87,2.56]$ & & $\downarrow$ \\
\hline Total events & 699 & & 241 & & & & & \\
\hline $\begin{array}{l}\text { Heterogeneity: } \mathrm{Chi}^{2} \\
\text { Test for overall effec }\end{array}$ & $\begin{array}{l}5.50, \mathrm{df}= \\
=9.70(\mathrm{~F}\end{array}$ & $\begin{array}{l}=19(P \\
P<0 . C\end{array}$ & $\begin{array}{l}=0.14) ; \mathbf{I}^{\prime} \\
0001)\end{array}$ & $=25 \%$ & & .0 & $\begin{array}{l}0.1 \\
\text { avours } 20 \mathrm{G}\end{array}$ & $\begin{array}{c}10 \\
\text { Favours } 23\end{array}$ \\
\hline
\end{tabular}

C

$20 \mathrm{G} 25 \mathrm{G}$

Odds Ratio

Odds Ratio

Study or Subgroup Events Total Events Total Weight M-H. Fixed, 95\% Cl $\quad$ M-H. Fixed, 95\% Cl Covert 2012

Sandali 2011

Scartozzi 2007

Shinoda 2008

Tan 2011

Wickham 2010

Yokota 2015

$\begin{array}{llllll}47 & 204 & 3 & 76 & 7.0 \% & 7.28[2.19,24.18]\end{array}$

$\begin{array}{lllllll}29 & 347 & 2 & 91 & 6.0 \% & 4.06[0.95,17.34]\end{array}$

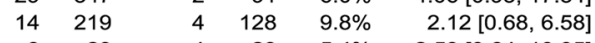

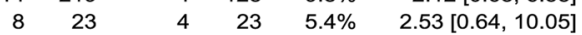

$\begin{array}{llllrr}6 & 29 & 13 & 87 & 10.7 \% & 1.48[0.51,4.35]\end{array}$

$\begin{array}{rrrrrr}5 & 21 & 1 & 18 & 1.7 \% & 5.31[0.56,50.55]\end{array}$

$\begin{array}{rrrrr}5 & 21 & 1 & 18 & 1.7 \% \\ 60 & 170 & 45 & 174 & 59.5 \%\end{array}$

$5.31[0.56,50.55]$
$1.56[0.98,2.48]$

Total $(95 \% \mathrm{Cl})$

1013

$597 \quad 100.0 \%$

$2.27[1.62,3.18]$

$\begin{array}{lll}\text { Total events } & 169 & 72 \\ \text { Heterogeneity: } \mathrm{Chi}^{2}=7.93, \mathrm{df}=6(\mathrm{P}=0.24) ; \mathrm{I}^{2}=24 \%\end{array}$

Test for overall effect: $Z=4.78(P<0.00001)$

Fig. 1 Odds ratio of appearance of iatrogenic retinal breaks in microincision vitrectomy surgery with conventional 20 -gauge vitrectomy. a 23-gauge or 25-guage vitrectomy, b 23-gauge vitrectomy only, c 25-gauge vitrectomy only. G gauge, MIVS microincision vitrectomy surgery 


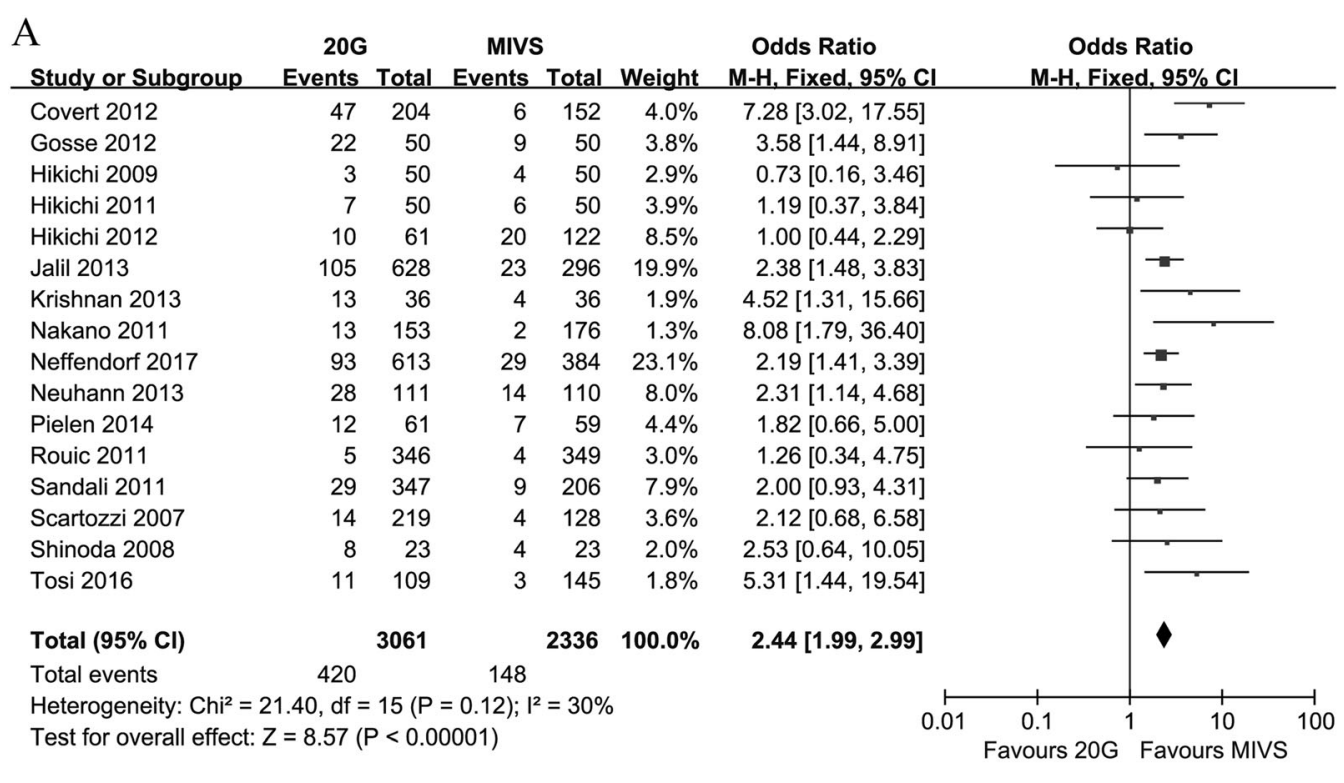

\begin{tabular}{|c|c|c|c|c|c|}
\hline Study or Subgroup & $\begin{array}{r}20 G \\
\text { Events }\end{array}$ & Total & $\begin{array}{r}\text { MIVS } \\
\text { Events }\end{array}$ & & Weight \\
\hline Covert 2012 & 12 & 204 & 6 & 152 & $19.2 \%$ \\
\hline Dihowm 2015 & 2 & 37 & 2 & 105 & $2.9 \%$ \\
\hline Goncu 2011 & 1 & 31 & 0 & 33 & $1.4 \%$ \\
\hline Haas 2010 & 3 & 167 & 1 & 64 & $4.2 \%$ \\
\hline Hikichi 2012 & 0 & 61 & 2 & 122 & $4.9 \%$ \\
\hline Jalil 2013 & 7 & 628 & 2 & 296 & $8.0 \%$ \\
\hline Pielen 2014 & 6 & 61 & 0 & 59 & $1.3 \%$ \\
\hline Rizzo 2010 & 7 & 570 & 31 & 1862 & $42.5 \%$ \\
\hline Rouic & 17 & 346 & 4 & 349 & $11.2 \%$ \\
\hline Sandali 2011 & 3 & 347 & 0 & 206 & $1.8 \%$ \\
\hline Tosi 2016 & 2 & 109 & 0 & 145 & $1.2 \%$ \\
\hline Valmaggia 2007 & 3 & 64 & 0 & 75 & $1.3 \%$ \\
\hline Total $(95 \% \mathrm{Cl})$ & \multicolumn{3}{|c|}{2625} & 3468 & $100.0^{\circ}$ \\
\hline Total events & 63 & \multicolumn{4}{|c|}{48} \\
\hline $\begin{array}{l}\text { Heterogeneity: Ch } \\
\text { Test for overall eff }\end{array}$ & $\begin{array}{l}6, \mathrm{df} \\
3.07\end{array}$ & $1(\mathrm{P}$ & 0); $1^{2}$ & $=14 \%$ & \\
\hline
\end{tabular}

Fig. 2 Subanalysis estimating the odds ratio of iatrogenic retinal breaks and postoperative retinal detachments in microincision vitrectomy surgery vs. conventional 20-gauge vitrectomy for macular

random-effects model was applied to the data, otherwise a fixed-effects model was used. Publication bias was assessed by Begg's rank correlation test and Egger's linear regression test $(P<0.05$ was considered representative of significant statistical publication bias) $[18,19]$.

\section{Results}

\section{Overall characteristics of selected studies and quality assessment}

Initially, a total of 2173 articles were identified. We excluded 2141 studies according to the exclusion criteria listed above. Hence, 32 studies were included in this metaanalysis [5-14, 20-41]. The flow diagram of the search
Odds Ratio Odds Ratio

M-H, Fixed, 95\% Cl M-H, Fixed, $95 \% \mathrm{Cl}$

$1.52[0.56,4.15]$

$2.94[0.40,21.68]$

$3.30[0.13,83.97]$

$1.15[0.12,11.29]$

$0.39[0.02,8.29]$

$1.66[0.34,8.03]$

$13.94[0.77,253.19]$

$0.73[0.32,1.68]$

$4.46[1.48,13.38]$

$4.20[0.22,81.64]$

$6.77[0.32,142.41]$

$8.59[0.44,169.57]$

$1.89[1.26,2.85]$

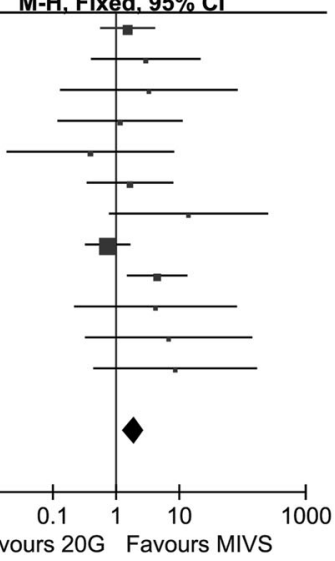

diseases. a Iatrogenic retinal breaks, b postoperative retinal detachments. G gauge, MIVS microincision vitrectomy surgery

procedure and results is summarized in Supplementary Appendix 1. Most of the studies were retrospective, except three prospective studies [20, 22, 41], and three RCTs [30, $38,39]$. According to the NOS used for quality assessment for nonrandomized studies, 14 studies had high quality scores of 7 , while 15 studies had moderate quality scores of 6 . The average score of all studies included in this metaanalysis was 6.48. All the RCTs fulfilled the quality criteria (3 points or more), according to the Jadad scale. In total, there were 14,373 eyes included in the meta-analysis: 6932 eyes were included in the $20 \mathrm{G}$ vitrectomy group, and 7441 eyes were included in the MIVS group $(23 \mathrm{G}$ or $25 \mathrm{G})$. No studies allowing comparison with $27 \mathrm{G}$ MIVS were identified as a result of the search. The characteristics of the studies included in the meta-analysis are summarized in Table 1. 

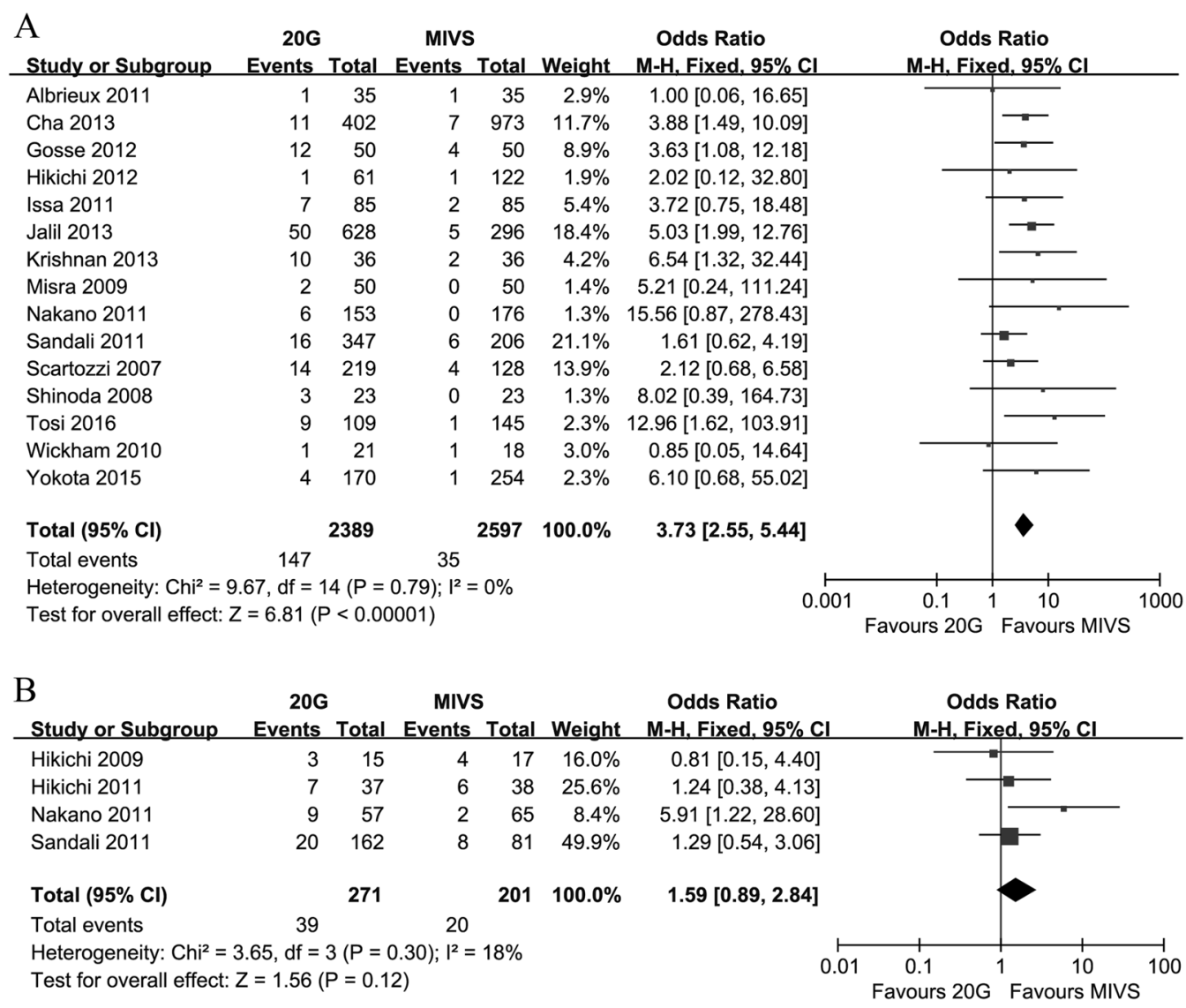

Fig. 3 Subanalysis estimating the odds ratio of iatrogenic retinal breaks in microincision vitrectomy surgery vs. conventional 20-gauge vitrectomy for: a sclerotomy-related retinal breaks or b PVD-related

\section{Estimated effects of MIVS on incidence of IRBs and postoperative RDs}

Twenty-six studies involving 11,275 eyes compared the rate of IRBs in $20 \mathrm{G}$ vitrectomy vs. the rate in MIVS. The overall incidence of IRBs was $12.78 \%$ (771 eyes per 6033 cases) for $20 \mathrm{G}$ vitrectomy, and $6.29 \%$ (330 eyes per 5242 cases) for all types of MIVS. The primary comparison clearly demonstrated that the incidence of IRBs was significantly higher in $20 \mathrm{G}$ vitrectomy than in $23 \mathrm{G} / 25 \mathrm{G}$ MIVS $(\mathrm{OR}=2.22,95 \% \mathrm{CI}, \quad 1.93-2.57, P<0.00001)$ (Fig. 1a). In a subgroup analysis based on different types of MIVS ( $23 \mathrm{G}$ or $25 \mathrm{G}$ ), we also found an increased risk of IRBs in $20 \mathrm{G}$ vitrectomy compared to $23 \mathrm{G}$ MIVS (OR $=$ $2.19,95 \%$ CI, 1.87-2.56, $P<0.00001)$ and also compared to $25 \mathrm{G}$ MIVS $(\mathrm{OR}=2.27,95 \% \mathrm{CI}, 1.62-3.18, P<$ 0.00001 ) (Fig. 1b, c). A sub-analysis in cases involving macular surgery only also demonstrated higher incidence of IRBs in $20 \mathrm{G}$ vitrectomy vs. $23 \mathrm{G} / 25 \mathrm{G}$ vitrectomy (OR = 2.44, 95\% CI, 1.99-2.99, $P<0.00001$ ) (Fig. 2a). In a further subgroup analysis, 15 studies involving 4986 eyes compared the rate of IRBs related to sclerotomy, and 4 studies involving 472 eyes reported IRBs associated with retinal breaks. G gauge, MIVS microincision vitrectomy surgery, PVD posterior vitreous detachment

PVD during vitrectomy between these two groups. The result of this subgroup analysis demonstrated an increased risk of sclerotomy-related retinal breaks in $20 \mathrm{G}$ vitrectomy compared with $23 \mathrm{G} / 25 \mathrm{G}$ MIVS (OR $=3.73,95 \% \mathrm{CI}, 2.55$ $-5.44, P<0.00001$ ) (Fig. 3a), but not for the same comparison in surgically induced PVD-related retinal breaks $(\mathrm{OR}=1.59,95 \% \mathrm{CI}, 0.89-2.84, P=0.12)$ (Fig. 3b).

In the second part of our meta-analysis, we compared the rate of RD after surgery related to the size of instrumentation used. Eighteen studies involving 7022 eyes compared the rate of postoperative RDs in $20 \mathrm{G}$ vitrectomy vs. the rate in $23 \mathrm{G} / 25 \mathrm{G}$ MIVS. The overall incidence of postoperative RDs was $2.52 \%$ (76 eyes per 3010 cases) for $20 \mathrm{G}$ vitrectomy vs.1.57\% (63 eyes per 4012 cases) for MIVS (Table 1). The meta-analysis demonstrated a higher incidence of postoperative RDs in $20 \mathrm{G}$ vitrectomy compared to that of $23 \mathrm{G} / 25 \mathrm{G}$ MIVS $(\mathrm{OR}=1.72,95 \% \mathrm{CI}, 1.21-2.46$, $P=0.003$ ) (Fig. 4a). In a subgroup analysis based on different types of MIVS ( $23 \mathrm{G}$ or $25 \mathrm{G}$ ), we also found an increased risk of postoperative RDs in $20 \mathrm{G}$ vitrectomy compared to $23 \mathrm{G}$ MIVS (OR $=2.45,95 \% \mathrm{CI}, 1.50-4.00$, $P=0.0003)$, but not for $25 \mathrm{G}$ MIVS $(\mathrm{OR}=1.01,95 \% \mathrm{CI}$, $0.63-1.64, P=0.96$ ) (Fig. 4b, c). When a subanalysis 

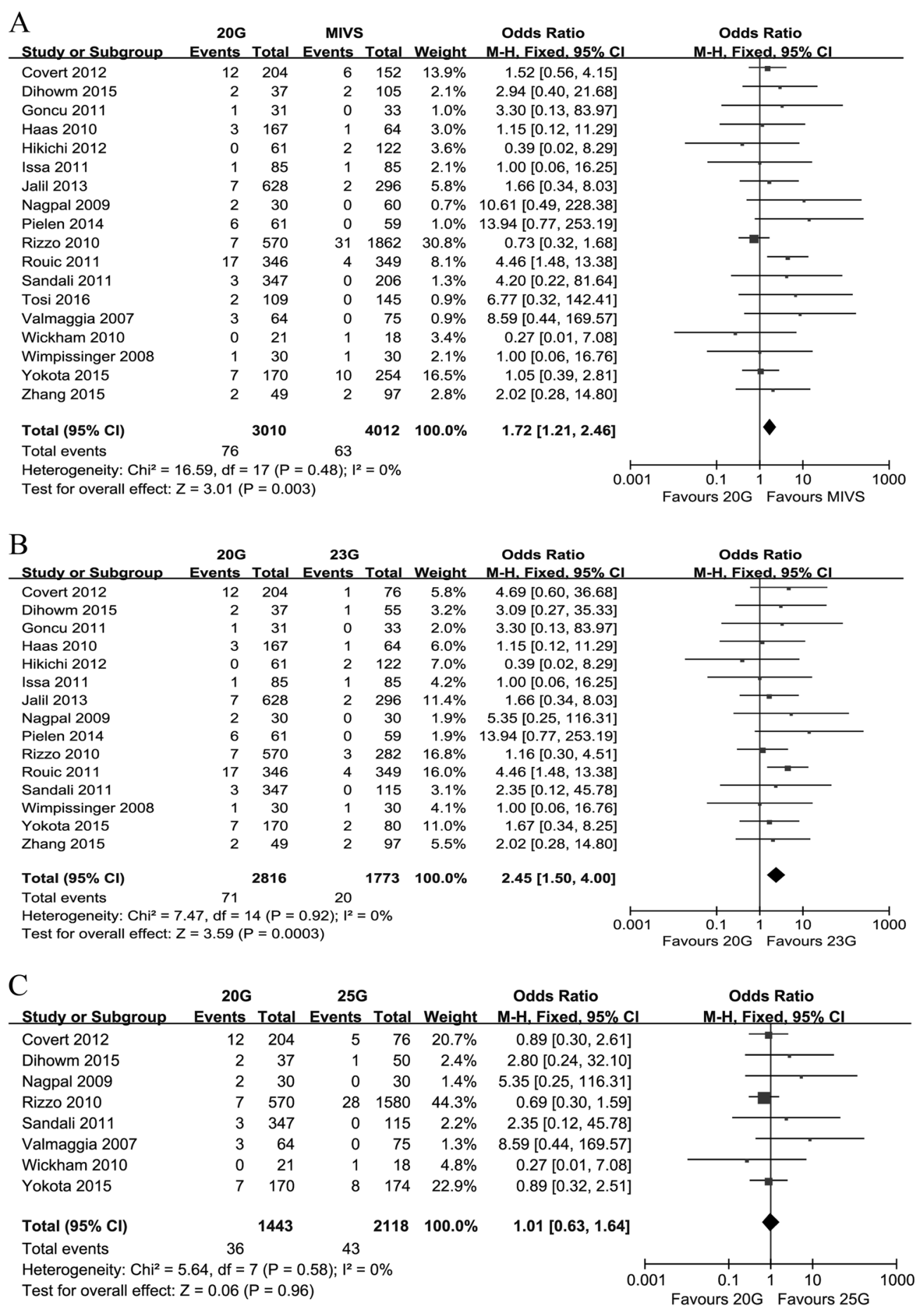

Fig. 4 Odds ratio of postoperative retinal detachments in microincision vitrectomy surgery with conventional 20 -gauge vitrectomy. a 23gauge or 25-guage vitrectomy, b 23-gauge vitrectomy only, c 25-

including only cases of macular surgery was conducted, it also demonstrated higher incidence of RDs in $20 \mathrm{G}$ vitrectomy vs. $23 \mathrm{G} / 25 \mathrm{G}$ vitrectomy ( $\mathrm{OR}=1.89,95 \% \mathrm{CI}$, $1.26-2.85, P=0.002$ ) (Fig. 2b). gauge vitrectomy only. G gauge, MIVS microincision vitrectomy surgery

In studies comparing IRBs incidence rate, slightly more than half of the studies, 15 out of 26 studies $(57.7 \%)$ in $20 \mathrm{G}$ and 14 out of 27 studies (53.8\%) in 23 G/25 G MIVS have less than 100 cases per group. Similarly, in studies reporting 
RDs, 10 out of $18(55.6 \%)$ in $20 \mathrm{G}$ and 9 out of 18 in $23 \mathrm{G} /$ $25 \mathrm{G}$ MIVS $(50.0 \%)$ have less than 100 cases per group. Therefore we conducted a subanalysis that only included the studies having more than 100 cases per group. The results of this subanalysis also demonstrated higher incidence of IRBs and postoperative RDs in $20 \mathrm{G}$ vitrectomy than in MIVS $(\mathrm{OR}=2.32,95 \% \mathrm{CI}, 1.97-2.72, \quad P<$ 0.00001 and $\mathrm{OR}=1.53,95 \% \mathrm{CI}, 1.01-2.32, P=0.04$ respectively) (Supplementary Appendix 2).

In addition, there were no publication bias in IRBs between the $20 \mathrm{G}$ vitrectomy and $23 \mathrm{G} / 25 \mathrm{G}$ MIVS (Begg's test, $P=0.947$; Egger's test, $P=0.585)$ and in postoperative RDs (Begg's test, $P=0.449$; Egger's test, $P=$ $0.135)$.

\section{Discussion}

This meta-analysis included 32 relevant studies from different locations (18 from Europe, 11 from Asia and 3 from N. America), representing a wide geographic origin. It showed that the incidence rate of IRBs in $20 \mathrm{G}$ vitrectomy was $12.78 \%$ (771/6033), while it was $6.29 \%(330 / 5242)$ in $23 \mathrm{G} / 25 \mathrm{G}$ MIVS, and the incidence rate of postoperative RDs in $20 \mathrm{G}$ vitrectomy was $2.52 \%$ (76/3010), while it was $1.57 \%$ (63/4012) in $23 \mathrm{G} / 25 \mathrm{G}$ MIVS. The meta-analysis demonstrated that the rates of IRBs and postoperative RDs in conventional $20 \mathrm{G}$ procedure were higher compared to the rates in MIVS, and similar results were obtained in a subanalysis based on macular surgery. Similar difference in incidence was shown in another subanalysis for the comparison of sclerotomy-related retinal breaks, but not for surgically induced PVD-related retinal breaks.

Although MIVS have gained considerable popularity as a preferred method for the treatment of several vitreoretinal diseases, the use of $20 \mathrm{G}$ vitrectomy has retained some popularity in some parts of the world. Thus, a recent paper by Fang et al. [42]. indicates that in $2015 \sim 15 \%$ of all vitrectomies were done with a $20 \mathrm{G}$ system at the Eye, Ear, Nose and Throat Hospital of Fudan University, Shanghai, China. A recent survey among 78 vitreoretinal surgeons from German-speaking countries indicated that $19.5 \%$ still use $20 \mathrm{G}$ vitrectomy [43]. Another recent study by Tayyab et al. [44]. used equal number of patients (42/42) for $20 \mathrm{G}$ vs. $23 \mathrm{G}$ vitrectomy in Al Ehsan Eye Hospital, Lahore from June 2016 to March 2017. Another recent study by Ghasemi et al. [45]. used $22 / 20$ patients for $20 \mathrm{G}$ vs. $23 \mathrm{G}$ vitrectomy in Tehran, Iran.

Iatrogenic retinal breaks are known as some of the most important and serious complications in vitreoretinal surgery [4]. Excessive vitreous traction on the retina is the leading cause of such breaks [46]. Several mechanisms can cause abnormal vitreoretinal traction during vitrectomy, including insertion of surgical instruments which causes traction on the adjacent vitreous base, or incarceration of vitreous in the sclerotomy site during withdrawal of instruments [47]. Iatrogenic retinal breaks located away from the entry sites are typically related to separation of the vitreous or epiretinal membranes from the retinal surface during surgery. Furthermore, intraoperative induction of PVD has been identified as an important cause of IRBs during surgery [48].

The results of the current meta-analysis clearly revealed that the incidence of IRBs associated with MIVS was significantly $(\sim 50 \%)$ lower compared to the incidence associated with $20 \mathrm{G}$ vitrectomy, especially for sclerotomyrelated retinal breaks. This difference may be due to several factors. One of the key factors may be the use of microcannulas, which remain within the sclerotomies for the duration of the surgery for the instruments to pass through. The cannulas may be long enough to traverse the vitreous base, enabling instruments to pass repeatedly into the eye without engaging vitreous gel around pars plana leading to less traction and fewer IRBs [27]. The higher cutting rate of a vitreous cutter may also reduce the incidence of IRBs. The $23 \mathrm{G} / 25 \mathrm{G}$ MIVS cutters typically have a higher maximum cut rate of $2500 / 5000$ cuts per minute compared with up to 1800 cuts per minute for $20 \mathrm{G}$ cutters $[26,45]$. Higher cut rates result in a lower volume of aspirated tissue per cut at a fixed flow, resulting in less tissue traction, which may affect break rate [26, 49]. Furthermore, the traction range of $20 \mathrm{G}$ cutters is higher compared to the traction range of $23 \mathrm{G} / 25$ G. Thus, pneumatic $20 \mathrm{G}$ cutters had a traction range of 2.06-37.22 dynes vs. 3.85-15.38 dynes for $23 \mathrm{G}$ and 5.13 -27.91 dynes for $25 \mathrm{G}$ and the traction range for electric 20 $\mathrm{G}$ cutters was even higher (3.60-41.78 dynes) [50]. This difference in traction caused by the cutters may also affect the risk of IRBs. Another factor influencing the difference may be flow through the probes. Maximum flow through the $20 \mathrm{G}$ probes was roughly two times higher than through the $23 \mathrm{G}$ probes and approximately six times higher than 25 $\mathrm{G}$ probes [51]. The smaller instruments and slower fluidics in MIVS may reduce the occurrence of IRBs. Additionally, the $20 \mathrm{G}$ cutter typically has a tip to port distance of 0.38 $\mathrm{mm}$, while the corresponding distance for the $23 \mathrm{G}$ cutters is typically $0.23 \mathrm{~mm}$ [26]. The reduced cutter tip to port distance allows greater use of cutter to delaminate and dissection epiretinal membranes while cutting, so the scissors are less frequently required during surgery. This difference in surgical technique may reduce the incidence of IRBs as less needed to exchange surgical instruments during surgery. It has to be noted that, in contrast to the incidence of IRBs related to other factors, the rate of retinal breaks related to PVD induction did not differ between MIVS and $20 \mathrm{G}$ vitrectomy in this meta-analysis. The surgical maneuvers for initiating and propagating induction of PVD are 
essentially the same, independent of the gauge of the vitreous instruments, so the propensity for occurrence of retinal breaks associated with surgically induced PVD may not differ even with a small-incision vitrectomy system [9, 47].

Postoperative RD is the most common vision-threatening complication after vitreoretinal surgery [38]. The rate of postoperative RDs was significantly lower in the $23 \mathrm{G} / 25 \mathrm{G}$ MIVS group than in the $20 \mathrm{G}$ vitrectomy group in this metaanalysis. The higher rate of postoperative RDs which were associated with $20 \mathrm{G}$ vitrectomy may be accounted for the higher rate of IRBs encountered in this type of surgery, for some of them may later result in RDs. The oblique, tunnelized, smaller size of the sclerotomy in MIVS may reduce the possibility of incarceration of a vitreous wick in the sclerotomy, when compared with a traditional direct, sutured incision. Vitreous incarcerated in the sclerotomy or around the sclerotomy may cause shrinkage and consequently induce a retinal break postoperatively, which can result in an RD [52]. In the subanalysis, we found a decreased risk of postoperative RDs in $23 \mathrm{G}$ MIVS compared to $20 \mathrm{G}$ vitrectomy, but not for $25 \mathrm{G}$ MIVS. The flexibility of the $25 \mathrm{G}$ instruments makes the removal of the peripheral vitreous more difficult than $20 \mathrm{G}$ instruments, while such problem is less pronounced with the $23 \mathrm{G}$ system because of the increased stiffness of the tools. The $23 \mathrm{G}$ MIVS possibly makes a better cleaning of the vitreous around the sclerotomies at the conclusion of vitrectomy than $25 \mathrm{G}$ MIVS, which may also influence the incidence of RDs.

Several limitations of this work should be acknowledged. First, a potential source of heterogeneity is the different type of surgical indications included in this analysis, although we found similar results in the subgroup analysis based on macular surgery or nonmacular surgery, the results should be interpreted with caution. Second, most of studies included in the meta-analysis were retrospective. Retrospective studies have inherent biases and may not accurately reflect the true incidence of IRBs and postoperative RDs. Thus, prospective or randomized clinical trials of larger sample size are needed to provide more definitive information. Third, it was not possible to stratify the studies based on types of vitrectomy cutters used (as the type of cutters are rarely reported). As shown by Teixeira et al. [50], electric $20 \mathrm{G}$ cutters have generally higher range of traction compared to pneumatic $20 \mathrm{G}$ cutters. Therefore, in theory, it is possible that use of electric $20 \mathrm{G}$ cutters accounts for most (if not all) of the increased incidence of IRMs and RDs. An additional limitation is that many studies do not report a detailed list and a breakdown of the vitreoretinal conditions used as an indication for surgery, which limited the current study to a subanalysis of macular vs. nonmacular conditions. Finally, the majority of the studies included in the meta-analysis are based on relatively small numbers.
However, there was no obvious tendency for series with fewer cases to show different results compared with reports including more cases.

In conclusion, our findings indicate that MIVS is associated with a much lower incidence of IRBs compared to conventional $20 \mathrm{G}$ vitrectomy for vitreoretinal surgery, especially for sclerotomy-related retinal breaks. Similarity, MIVS has a lower incidence of postoperative RDs, especially for $23 \mathrm{G}$ MIVS.

\section{Summary}

\section{What was known before}

The microincision vitrectomy surgery may carry similar risk of choroidal detachment and vitreous hemorrhage. But iatrogenic retinal breaks and postoperative retinal detachments are uncertained.

\section{What this study adds}

The microincision vitrectomy surgery may be superior to conventional 20-gauge vitrectomy in reducing the incidence of iatrogenic retinal breaks and postoperative retinal detachments.

\section{Acknowledgements}

Funding This work was supported by the National Natural Science Foundation of China (No. 81570875 to WSL), Welfare Technology Applied Research Program Fund of Science Technology Department of Zhejiang Province (No. LGF18H120002 to YHT) and Quzhou Science and Technology Project (No. 20172041 to GHC).

\section{Compliance with ethical standards}

Conflict of interest The authors declare that they have no conflict of interest.

\section{References}

1. O'Malley C, Heintz RM, Sr. Vitrectomy with an alternative instrument system. Ann Ophthalmol. 1975;7:585-8.591-4.

2. Zhang ZH, Liu HY, Wimpissinger B, Avitabile T, Xu X, Liu K. Transconjunctival sutureless vitrectomy versus 20 -gauge vitrectomy for vitreoretinal surgery: a meta-analysis of randomized controlled trials. Graefes Arch Clin Exp Ophthalmol. 2013;251:681-8.

3. Chen G, Tzekov R, Li W, Jiang F, Mao S, Tong Y. Incidence of endophthalmitis after vitrectomy: a systematic review and metaanalysis. Retina. 2018. https://doi.org/10.1097/IAE. 0000000000002055. e-pub ahead of print. 23 January 2018

4. Moore JK, Kitchens JW, Smiddy WE, Mavrofrides EC, Gregorio G. Retinal breaks observed during pars plana vitrectomy. Am J Ophthalmol. 2007;144:32-36. 
5. Covert DJ, Henry CR, Bhatia SK, Croskrey J, Sanchez CR, Han DP. Intraoperative retinal tear formation and postoperative rhegmatogenous retinal detachment in transconjunctival cannulated vitrectomy systems compared with the standard 20-gauge system. Arch Ophthalmol. 2012;130:186-9.

6. Gosse E, Newsom R, Lochhead J. The incidence and distribution of iatrogenic retinal tears in 20-gauge and 23-gauge vitrectomy. Eye (Lond). 2012;26:140-3.

7. Hikichi T, Matsumoto N, Ohtsuka H, Higuchi M, Matsushita T, Ariga $\mathrm{H}$, et al. Comparison of one-year outcomes between 23- and 20-gauge vitrectomy for preretinal membrane. Am J Ophthalmol. 2009;147:639-43.

8. Haas A, seidel G, Steinbrugger I, Maier R, Gasser-Steiner V, Wedrich A, et al. Twenty-three-gauge and 20-gauge vitrectomy in epiretinal membrane surgery. Retina. 2010;30:112-6.

9. Hikichi T, Kosaka S, Takami K, Ariga H, Ohtsuka H, Higuchi M, et al. 23- and 20-gauge vitrectomy with air tamponade with combined phacoemulsification for idiopathic macular hole: a single-surgeon study. Am J Ophthalmol. 2011;152:114-21.

10. Hikichi T, Kosaka S, Takami K, Ariga H, Ohtsuka H, Higuchi M, et al. Incidence of retinal breaks in eyes undergoing 23-gauge or 20 -gauge vitrectomy with induction of posterior vitreous detachment. Retina. 2012;32:1100-5.

11. Pielen A, Guerra NI, Bohringer D, Junker B, Bühler AD, Stahl A, et al. Intra- and postoperative risks and complications of smallgauge (23-G) versus conventional (20-G) vitrectomy for macular surgery. Eur J Ophthalmol. 2014;24:778-85.

12. Le Rouic JF, Becquet F, Ducournau D. Does 23-gauge sutureless vitrectomy modify the risk of postoperative retinal detachment after macular surgery? A comparison with 20-gauge vitrectomy. Retina. 2011;31:902-8.

13. Sandali O, EI Sanharawi M, Lecuen N, Barale PO, Bonnel S, Basli E, et al. 25-, 23-, and 20-gauge vitrectomy in epiretinal membrane surgery: a comparattive study of 553 cases. Graefes Arch Clin Exp Ophthalmol. 2011;249:1811-9.

14. Rizzo S, Belting C, Genovesi-Ebert F, di Bartolo E. Incidence of retinal detachment after small-incision, sutureless pars plana vitrectomy compared with conventional 20 -gauge vitrectomy in macular hole and epiretinal membrane surgery. Retina. 2010;30:1065-71.

15. Stang A. Critical evaluation of the Newcastle-Ottawa scale for the assessment of the quality of nonrandomized studies in metaanalyses. Eur J Epidemiol. 2010;25:603-5.

16. Jadad AR, Moore RA, Carroll D, Jenkinson C, Reynolds DJ, Gavaghan DJ, et al. Assessing the quality of reports of randomized clinical trials: is blinding necessary? Control Clin Trials. 1996;17:1-12.

17. Lau J, Ioannidis JP, Schmid CH. Quantitative synthesis in systematic reviews. Ann Intern Med. 1997;127:820-6.

18. Begg CB, Mazumdar M. Operating characteristics of a rank correlation test for publication bias. Biometrics. 1994;50:1088-101.

19. Egger M, Smith GD, Schneider M, Minder C. Bias in metaanalysis detected by a simple, graphical test. BMJ. 1997;315:62934.

20. Albrieux M, Rouberol F, Bernheim D, Romanet JP, Chiquet C. Comparative study of 23-gauge vitrectomy versus 20 -gauge vitrectomy for the treatment of rhegmatogenous retinal detachment. Graefes Arch Clin Exp Ophthalmol. 2011;249:1459-68.

21. Cha DM, Woo SJ, Park KH, Chung H. Intraoperative iatrogenic peripheral retinal break in 23-gauge transconjunctival sutureless vitrectomy versus 20-gauge conventional vitrectomy. Graefes Arch Clin Exp Ophthalmol. 2013;251:1469-74.

22. Misra A, Ho-Yen G, Burton RL. 23-gauge sutureless vitrectomy and 20-gauge vitrectomy: a case series comparison. Eye (Lond). 2009;23:1187-91.
23. Park DH, Shin JP, Kim SY. Comparsion of clinical outcomes between 23 -gauge and 20 -gauge vitrectomy in patients with proliferative diabetic retinopathy. Retina. 2010;30:1662-70.

24. Dihowm F, MacCumber M. Comparison of outcomes between 20, 23 and 25 gauge vitrectomy for idiopathic macular hole. Int $\mathrm{J}$ Retin Vitr. 2015;1:6. eCollection 2015

25. Goncu T, Gurelik G, Hasanreisoglu B. Comparison of efficacy and safety between transconjunctival 23-gauge and conventional 20 -gauge vitrectomy systems in macular surgery. Korean J Ophthalmol. 2012;26:339-46.

26. Jalil A, Ho WO, Charles S, Dhawahir-Scala F, Patton N. Iatrogenic retinal breaks in 20-G versus $23-\mathrm{G}$ pars plana vitrectomy. Graefes Arch Clin Exp Ophthalmol. 2013;251:1463-7.

27. Issa SA, Connor A, Habib M, Steel DH. Comparison of retinal breaks observed during 23 gauge transconjunctival vitrectomy versus conventional 20 gauge surgery for proliferative diabetic retinopathy. Clin Ophthalmol. 2011;5:109-14.

28. Krishnan R, Tossounis C, Fung Yang Y. 20-gauge and 23-gauge phacovitrectomy for idiopathic macular holes: comparision of complications and long-term outcomes. Eye (Lond). 2013;27:7277.

29. Nakano T, Uemura A, Sakamoto T. Incidence of iatrogenic peripheral retinal breaks in 23-gauge vitrectomy for macular diseases. Retina. 2011;31:1997-2001.

30. Nagpal M, Wartikar S, Nagpal K. Comparison of clinical outcomes and wound dynamics of sclerotomy ports of 20, 25, and 23 gauge vitrectomy. Retina. 2009;29:225-31.

31. Neffendorf JE, Gupta B, Williamson TH. Intraoperative complications of patients undergoing small-gauge and 20-gauge vitrectomy: a database study of 4,274 procedures. Eur J Ophthalmol. 2017;27:226-30.

32. Neuhann IM, Hilgers RD, Bartz-Schmidt KU. Intraoperative retinal break formation in 23-/25-gauge vitrectomy versus 20-gauge vitrectomy. Ophthalmologica. 2013;229:50-53.

33. Scartozzi R, Bessa AS, Gupta OP, Regillo CD. Intraoperative sclerotomy-related retinal breaks for macular surgery, 20- vs 25gauge vitrectomy systems. Am J Ophthalmol. 2007;143:155-6.

34. Shinoda H, Shinoda K, Satofuka S, Imamura Y, Ozawa Y, Ishida $\mathrm{S}$, et al. Visual recovery after vitrectomy for macular hole using 25-gauge instruments. Acta Ophthalmol. 2008;86:151-5.

35. Tan HS, Mura M, Lesnik Oberstein SY, Bijl HM. Safety of vitrectomy for floaters. Am J Ophthalmol. 2011;151:995-8.

36. Tosi GM, Esposti P, Romeo N, Marigliani D, Cevenini G, Massimo $\mathrm{P}$, et al. The incidence of rhegmatogenous retinal complications in macular surgery after prophylactic preoperative laser retinopexy: a retrospective study. Med (Baltim). 2016;95:e3283.

37. Valmaggia. Pars plana vitrectomy with 25 -gauge instruments in the treatment of idiopathic epiretinal membranes. Klin Monbl Augenheilkd. 2007;224:292-6.

38. Wickham L, Bunce C, Kwan AS, Bainbridge J, Aylward GW. A pilot randomised controlled trial comparing the postoperative pain experience following vitrectomy with a 20 -gauge system and the 25-gauge transconjunctival system. Br J Ophthalmol. 2010;94:3640.

39. Wimpissinger B, Kellner L, Brannath W, Krepler K, Stolba U, Mihalics C, et al. 23-gauge versus 20-gauge system for pars plana vitrectomy: a prospective randomised clinical trial. $\mathrm{Br} \mathrm{J}$ Ophthalmol. 2008;92:1483-7.

40. Yokota R, Inoue M, Itoh Y, Rii T, Hirota K, Hirakata A. Comparison of microinsicion vitrectomy and conventional 20-gauge vitrectomy for severe proliferative diabetic retinopathy. Jpn J Ophthalmol. 2015;59:288-94.

41. Zhang J, Li Y, Zhao X, Yu X, Lu L. Comparison of clinical features after 20-gauge vitrectomy versus 23-gauge vitrectomy. Asia Pac J Ophthalmol (Phila). 2015;4:367-70. 
42. Fang Y, Ku H, Liu Y, Gan D. Trends in the characteristics of vitrectomy in Eastern China. Clin Ophthalmol. 2018;12:19932000.

43. Fischer CV, Kulanga M, Hoerauf $H$. Trends in retinal detachment surgery: what has changed compared to 2001? Ophthalmologe. 2018;115:663-8.

44. Tayyab H, Khan AA, Sadiq MAA, Karamat I. Comparison of 23 gauge transconjunctival releasable suture vitrectomy with standard 20 gauge vitrectomy. Pak J Med Sci. 2018;34: 328-32.

45. Ghasemi FK, Shaheen Y, Karimi MA, Aghaei H, Parvaresh MM, Bahmani KM, et al. Schirmer test changes after 20 gauge and 23 gauge pars plana vitrectomy. Rom J Ophthalmol. 2017; 61:39-43.

46. Sjaarda RN, Glaser BM, Thompson JT, Murphy RP, Hanham A. Distribution of iatrogenic retinal breaks in macular hole surgery. Ophthalmology. 1995;102:1387-92.
47. Tan HS, Oberstein SYL, Mura M, de Smet M. Enhanced internal research for iatrogenic retinal breaks in 20-gauge macular surgery. Br J Ophthalmol. 2010;94:1490-2.

48. Chung SE, Kim KY, Kang SW. Retinal breaks associated with the induction of posterior vitreous detachment. Am J Ophthalmol. 2009;147:1012-6.

49. Mura M, Barca F, Dell'Omo R, Nasini F, Peiretti E. Iatrogenic retinal breaks in ultrahigh-speed 25-gauge vitrectomy: a prospective study of elective cases. Br J Ophthalmol. 2016;100:1383-7.

50. Teixeira A, Chong LP, Matsuoka N, Arana L, Kerns R, Bhadri P, et al. Vitreoretinal traction created by conventional cutters during vitrectomy. Ophthalmology. 2010;117:1387-92.

51. Abulon DJ. Vitreous flow rates through dual pneumatic cutters: effects of duty cycle and cut rate. Clin Ophthalmol. 2015;9:253-61.

52. Rizzo S, Belting C, Genovesi-Ebert F. Retinal detachment after small-incision, sutureless pars plana vitrectomy: possible causative agents. Graefes Arch Clin Exp Ophthalmol. 2010;248:1401-6. 